\title{
International Journal of Medical Science and Health Research
}

Vol. 5, No. 03; 2021

ISSN: $2581-3366$

\section{The Effects of Workload on Nurses' Mental Health in Katutura State Hospital in Windhoek, Namibia}

\author{
Tangi Tupavali Lukolo ${ }^{1}$, Linda N Lukolo ${ }^{2}$, Lukanga Charles Kimera ${ }^{3}$ \\ ${ }^{1}$ Faculty of Humanities, University of Namibia \\ ${ }^{2}$ Department of Family and community medicine, School of Medicine, University of Namibia, \\ Windhoek, Namibia \\ ${ }^{3}$ Department of Obstetrics \& Gynaecology, School of Medicine, University of Namibia
}

doi: 10.51505/ijmshr.2021.5307

URL: http://dx.doi.org/10.51505/ijmshr.2021.5307

\begin{abstract}
Objective: Workload is the number of tasks and obligations that one has to perform or to complete within a specific period of time. The amount and type of work one does on a daily basis may have an effect on one's health particularly mental health. The objective of this research was to determine the effects of workload on nurses' mental health.

Materials \& methods: A quantitative descriptive design was employed with purposive sampling to select a sample of participants using a pre-tested questionnaire. The questionnaire was divided in five parts; the first part being the socio-demographic data, the second part was on workload, third part included questions on nursing shortages, the fourth part addressed issues of burnout and the final part addressed issues of mental health of nurses.

Results: Out of the 150 questionnaires handed out, 120 were returned by the participants. Ninety-four of the participants were females and 26 were males. The age range of the participants was 24-51years. The results of this study indicate that most nurses in Katutura Hospital are overworked and as a result present with symptoms of mental health classified as depression. Among other factors, staff shortage came out as a major contributing factor for the high levels of workload.
\end{abstract}

Keywords: Workload, Mental health, Stress and burnout

\section{Background}

Workload in general is defined as the amount of work performed or expected to be performed, usually within a specific period of time. Nurses' tasks are challenging as they primarily work with sick people, dying and grieving people (Rothmann, 2009). Healthcare workers, especially nurses/midwives, frequently work overtime, weekends \& public holidays and nights in order to care for the seriously ill and the injured patients (Foley, 2004). Irrespective of the risks of stress and other occupational hazards, many health care practitioners, including nurses, stay working in the health care systems for years and some remain engaged with their work forever (Cooper 2012). 


\section{International Journal of Medical Science and Health Research}

Vol. 5, No. 03; 2021

ISSN: 2581-3366

Health care workers, particularly nurses and midwives, are at a high risk of experiencing severe stress, burnout and both mental and physical illness. Workplace factors associated with stress can be categorised as those that are intrinsic to the job like long working hours, work overload, time pressure, lack of breaks, and poor physical work conditions (Arash, Ali \& Gholamreza, 2012). Job stress is one of the main factors that can decrease productivity of organizations (Arash, Ali \& Gholamreza, 2012). Nursing is a stressful profession as it requires prolonged and odd working hours and irregular work shifts. In recent years, the demand on nurses/midwives has increased, resulting in, for instance, labour shortage, reorganizations and mergers, shorter patient hospital stays and aging (De Jonge et al, 2010).

Schaufeli, 2003 described stress and burnout as an extreme reduction in energy and that burnout is characterised by three primary symptoms. Firstly, emotional exhaustion which refers to a depletion of emotional resources. Employees who are emotionally exhausted typically feel as though they lack the adaptive resources and cannot contribute any more to their job. The energy that they once had devoted to their work gets depleted, leaving them without resources to perform their work. Secondly, depersonalization, also known as disengagement. This often occurs in response to the aforementioned emotional exhaustion and describes a process whereby employees get detached from their job and develop unsympathetic or uncaring attitudes towards their job, their performance, and those associated with the job (e.g., clients, co-workers, etc.). Thirdly, reduced personal accomplishment (also known as personal efficacy). This refers to diminished perceptions of one's ability on the job; employees feel that they cannot perform well at their job as they once used to. (Schaufeli (2003).

According to the Namibia National Workload Indicators of Staffing Need report (2015), Namibia has a shortage of nurses and midwives (61\% of the workload-based requirements).

The relationship between work, the workplace and the tools of the workplace becomes an integral part of work itself (Soegoto, E. S., \& Narimawati, U. 2017). An organization's physical environment and its design and layout can affect employees' behaviour in the workplace. When the demands for increased productivity exceed the employees' ability to complete the job at hand in time, the employees may be pushed beyond what they can sustain. Nurses/midwives often experience a heavy workload to the extent that the quality of care given to patients becomes poor (Tummers et al, 2002).

Burnout occurs when a person does not have effective coping skills to deal with the demands of the work they are performing (Kamhisa et al, 2016).

In this study, we aimed at getting the clear insight of the effects of workload to nurses' mental health in Katutura Windhoek city, Namibia.

\section{Methods}

A quantitative descriptive design was employed with purposive sampling to select a sample of participants using a pre-tested questionnaire. The questionnaire was divided in five parts; the first part being the socio-demographic data, the second part was on workload, the third part included 


\section{International Journal of Medical Science and Health Research}

Vol. 5, No. 03; 2021

ISSN: 2581-3366

questions on nursing shortages, the fourth part addressed issues of burnout and the final part addressed issues of mental health of nurses. Male and female nurses/midwives/accoucheurs working at various wards and departments in Katutura Intermediate Hospital were targeted. One hundred and twenty participated in the study after signing a consent.

2.1 Ethical considerations: Permission to carry out the study on human subjects was obtained from Ministry of Health and Social Services. Participation was voluntary and each participant signed a consent form after through explanation of the aim of the study. The participants had the right to opt out of the study at any time. Confidentiality and anonymity were ensured during the study by using participants' initials instead of names and non-use of contact details.

2.2 Sampling method: Purposive sampling was employed for this study utilizing the nonprobability convenience sampling technique to include nurses/midwives/accoucheurs employed by Ministry of Health and Social Services in Katutura Hospital. Katutura is an intermediate hospital in Windhoek city of Namibia. It offers specialised services and it receives patients not only from the city but also from different regions of the country, and, for that matter, many times the number of patients is big. Katutura hospital was chosen as a representative hospital as almost all tertiary hospitals in Namibia have similar characteristics, in terms of staffing, to Katutura hospital. The hospital has many cadres of staff but nurses make the biggest percentage.

\section{Data analysis}

Statistical Package for Social Science (SPSS Version 25) was used for data entry and analysis. Descriptive statistics and analytical data were used to get means and standard deviations. Factor analysis was used to explore the analysed data for patterns, confirmation and reduction of many variables to a much more manageable quantity. Frequency test analysis was also carried out in order to cleanse the data. One sample t-test was done in order to test the research hypotheses. The t-test was used for analyses as the population mean as standard deviation values were not known

\section{Results}

\section{Demographic characteristics of the respondents}

\section{Gender}

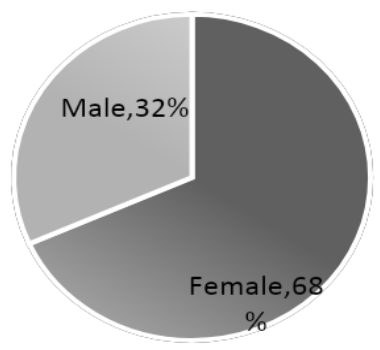




\section{International Journal of Medical Science and Health Research}

Vol. 5, No. 03; 2021

ISSN: 2581-3366

\section{Figure 1: Gender of respondents}

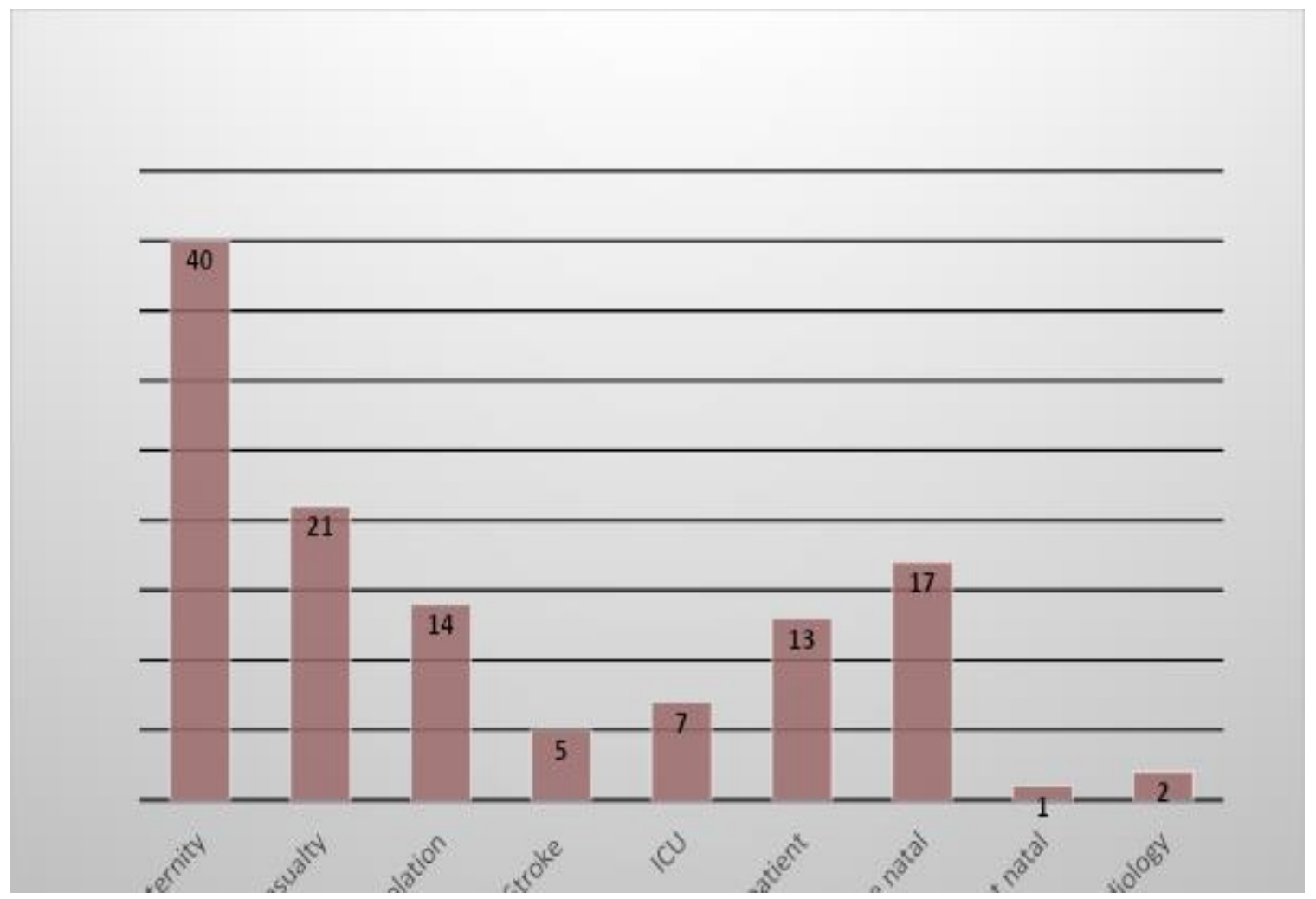

Figure 2: Respondents' Department/ward

Sixty-eight (68\%) of the participants were females while $32 \%$ were males. Majority (40) of the respondents were from Maternity ward, 21 from the Casualty department, 14 from TB isolation ward, 5 from Stroke Unit, 7 from the ICU ward, 13 from Outpatient ward, 17 from Ante natal ward (ANW), 1 from Post-natal ward and 2 from Cardiology ward.

(TB - Tuberculosis, ICU - Intensive Care Unit, ANW - Antenatal Ward)

Majority (44) (36.7\%) of respondents had been in employment with the hospital for a period of 1 to 2 years. Twenty-six (26) (21.7\%) had worked for the hospital of 3-4 years and 25 (20.8\%) respondents had worked for the hospital for less than 1 year. Twenty-five (25) (20.8\%) respondents had been in service for more than 4 years, of whom only $2(1.7 \%)$ had been in the same employment for over 10 years. This is evidence of a great turnover of the staff. The lower the number of years in service the lower the experience and this has a bearing on the quality of service. 


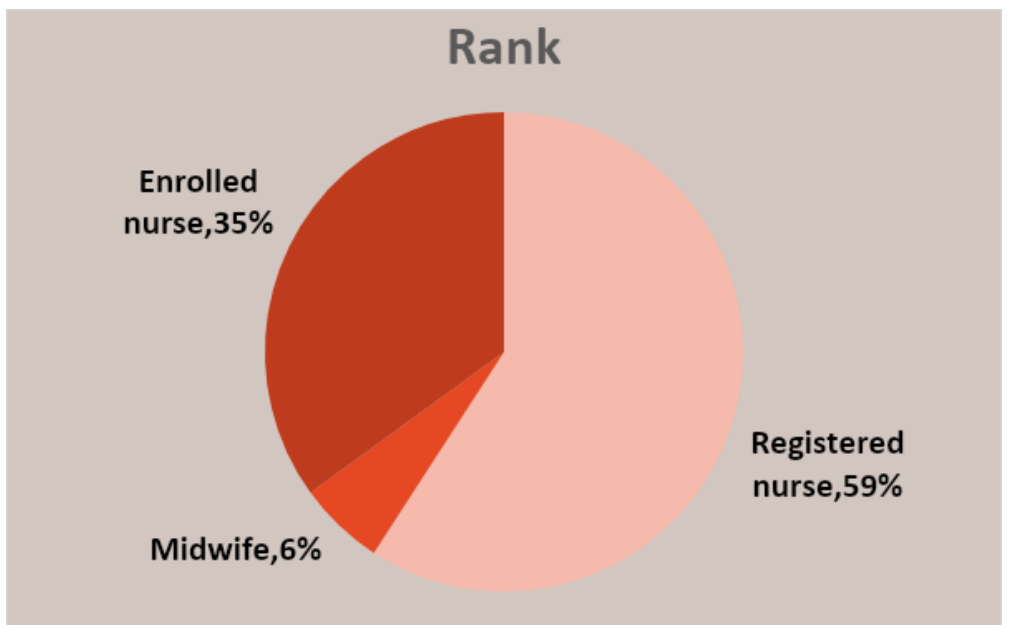

Figure 3: Rank of Respondents

Seventy-one (71) $(59 \%)$ of the respondents were registered nurses, $42(35 \%)$ were Enrolled nurses and 7 (6\%) were Midwives.

Although majority (40) (33.3\%) of the staff were from maternity ward (Figure 2), only 7 $(17.5 \%)$ of them were midwives. This is a very small percentage meaning that staff on maternity ward perform duties they are not trained to do - they have limited skills to perform such duties.

Majority (78) (65\%) of the respondents reported having no free time for social life, 37 (30.8\%) had little free time compared to the past and $5(4.2 \%)$ respondents were indifferent about the amount of free time at the time of data collection compared to the past.

Majority of the respondents (68) (57\%) had at one moment considered leaving the nursing profession. Of those who, at some moment, considered leaving the profession, 71 felt overworked, 27 did not enjoy their job anymore and 17 had other reasons (e.g., going for further studies). 


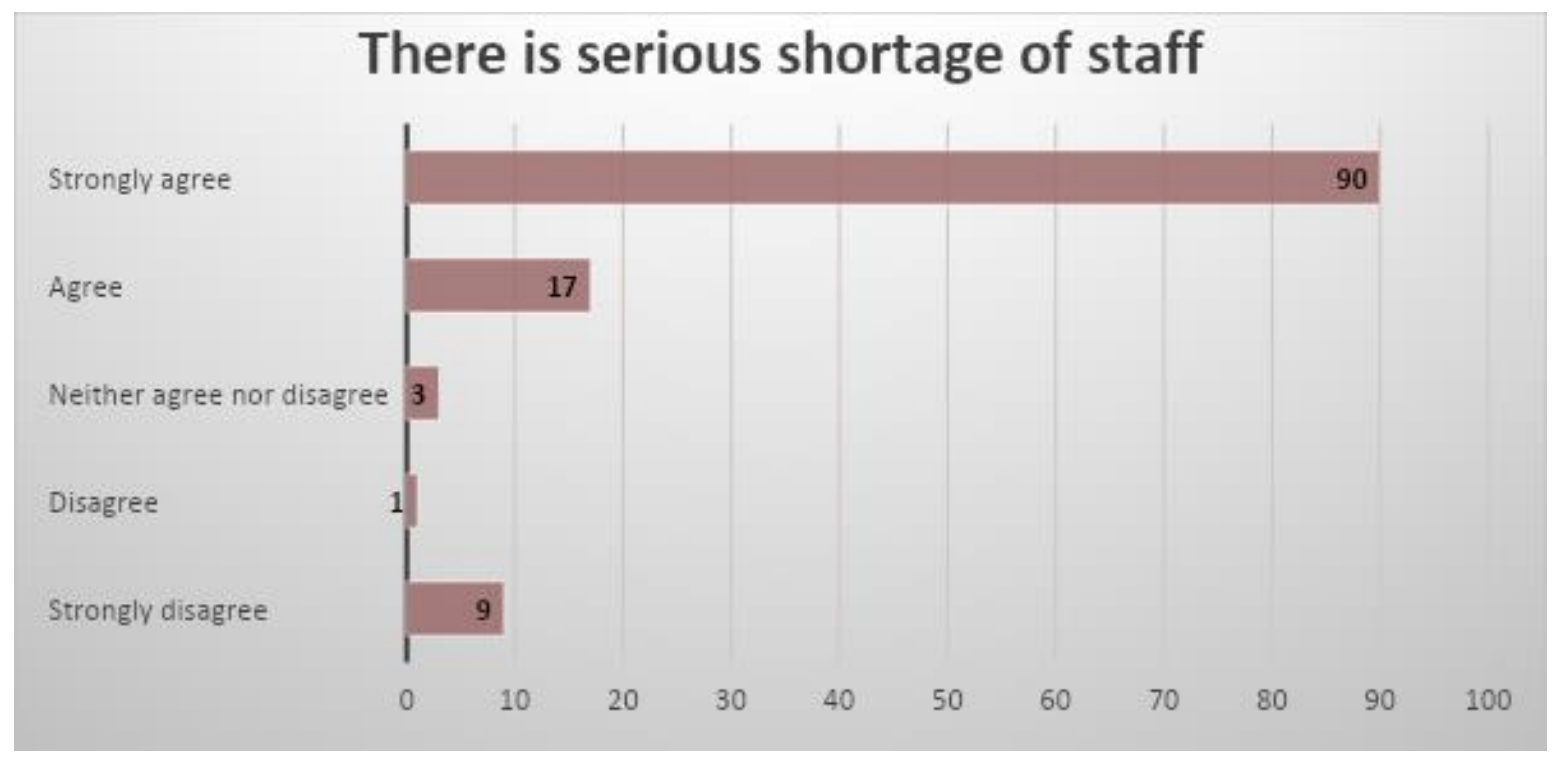

Figure 4: What staff think about Departmental staffing levels

One hundred and seven (107) (89.2\%) respondents agreed, 90 (75\%) of whom strongly agreed that there is a serious shortage of nurses in their facility.

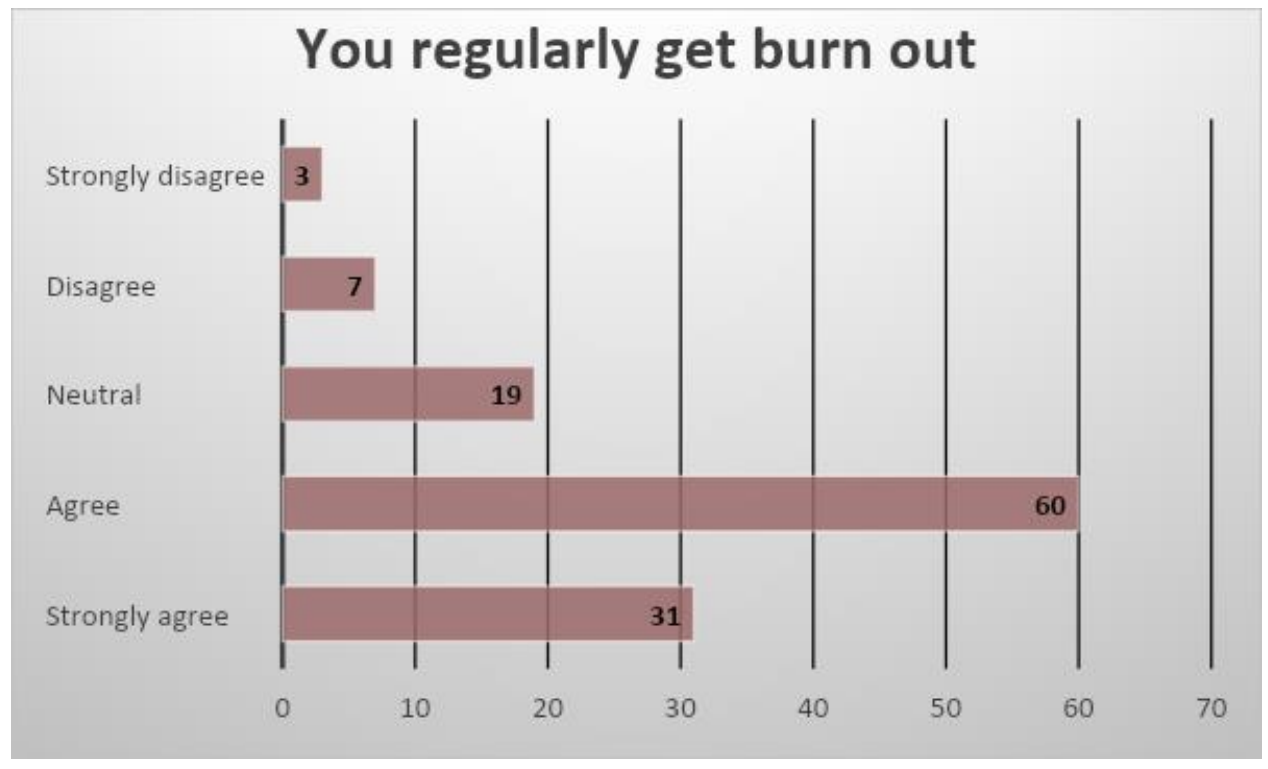

Figure 5: Effect of understaffing to the available staff

Ninety-one (75.8\%) of participants agreed, 31 (25.8\%) of whom strongly agreed that they regularly get burnout at work 


\section{What symptoms of burn out do you experience?}

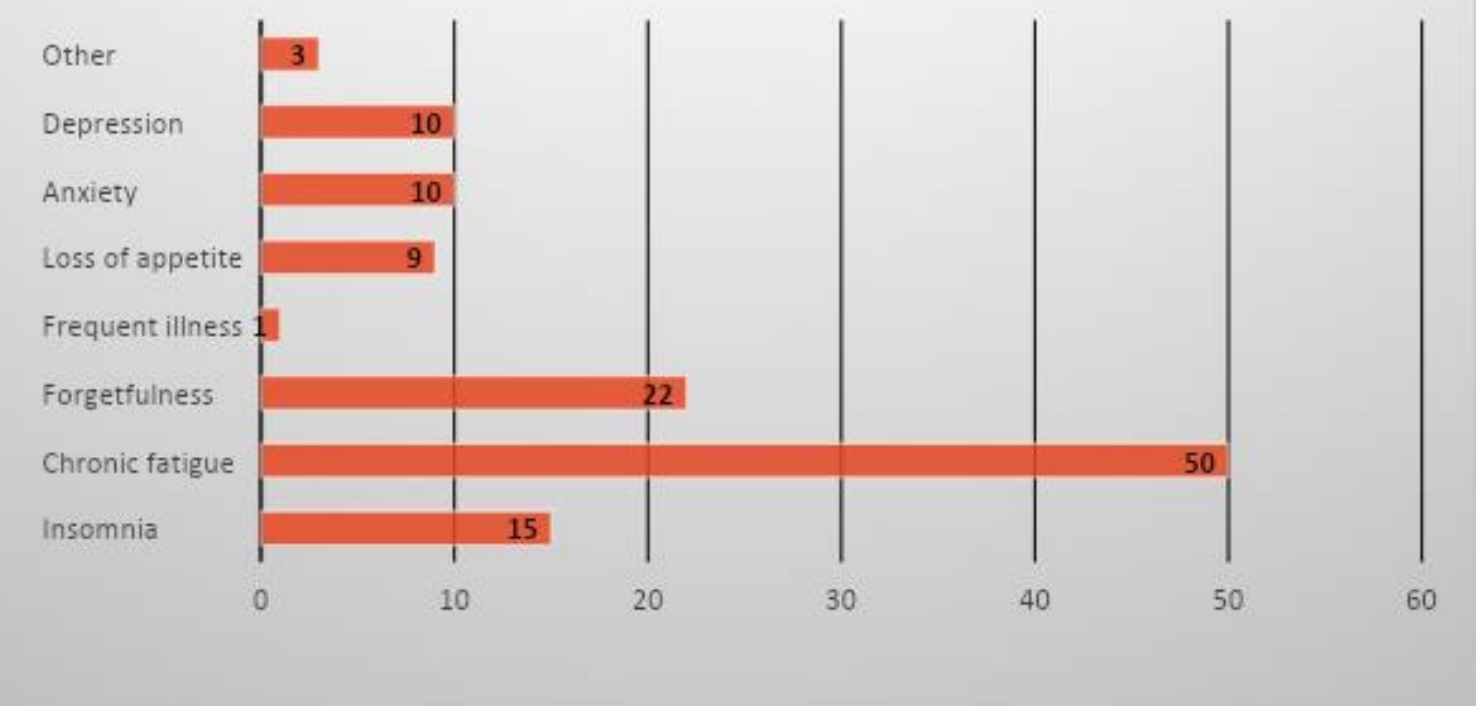

Figure 6: Symptoms of burn out staff get

Majority (50) (41.7\%) of the respondents indicated that they often feel chronically fatigued; 22 $(18.3 \%)$ indicated that they get symptoms of forgetfulness; $15(12.5 \%)$ indicated that they get insomnia. Other symptoms included anxiety 10 (8.3\%), depression (10) (8.3\%), loss of appetite (9) $(7.5 \%)$, mood swings and frequent illness.

Forty-three (43) (35.8\%) of the respondents indicated that they have little time for socialization; 31 (25.8) respondents indicated that burn out leads to poor quality of patient care; 17 (14.2\%) indicated that burn out leads to poor family relationships and sometimes breakdown of relationships; $19(15.8 \%)$ respondents indicated that their personal health is affected as a result of burnout in that they tend to be ill most of the time. Other effects of burn out included lack of job satisfaction and poor working relationship with colleagues.

\section{Psychometric properties of instruments}

\begin{tabular}{|lcc|}
\hline Variable & Number of items & Cronbach's Alpha \\
Mental health & 3 & 0.701 \\
\hline
\end{tabular}

Table 1: Reliability estimate of mental health and workload variables

Only the variables that represent consistency were selected to determine the Cronbach Alpha coefficient on both 'Mental health' and 'Workload'. Table 1 presents information on the dimensions of mental health and workload. The two variables were combined to calculate the 


\section{International Journal of Medical Science and Health Research}

Vol. 5, No. 03; 2021

ISSN: 2581-3366

Cronbach's Alpha coefficient which is 0.701. Cronbach's Alpha coefficient of 0.701 indicates a highly reliable measurement instrument in terms of mental health and workload.

\section{Correlational Analyses}

Correlations

\begin{tabular}{|ll|l|l|l|l|}
\hline & & $\begin{array}{l}\text { Workloa } \\
\mathrm{d}\end{array}$ & $\begin{array}{l}\text { Nursing } \\
\text { shortage }\end{array}$ & $\begin{array}{l}\text { Nurse } \\
\text { burnout }\end{array}$ & Mental health \\
\hline \multirow{3}{*}{ Workload } & Pearson Correlation & 1 & -0.092 & $0.258^{*}$ & $-0.398^{* *}$ \\
& Sig. (2-tailed) & & 0.380 & 0.012 & 0.000 \\
& $\mathrm{~N}$ & 94 & 93 & 94 & 94 \\
Nursing & Pearson Correlation & -0.092 & 1 & -0.004 & $0.242^{* *}$ \\
\multirow{5}{*}{ Nurse burnoutage } & Sig. (2-tailed) & 0.380 & & 0.968 & 0.009 \\
& N & 93 & 116 & 116 & 116 \\
& Pearson Correlation & $0.258^{*}$ & -0.004 & 1 & -0.073 \\
& Sig. (2-tailed) & 0.012 & 0.968 & & 0.427 \\
& N & 94 & 116 & 120 & 120 \\
& Pearson Correlation & $-0.398^{* *}$ & $0.242^{* *}$ & -0.073 & 1 \\
& Sig. (2-tailed) & 0.000 & 0.009 & 0.427 & \\
& N & 94 & 116 & 120 & 120 \\
\hline
\end{tabular}

Table 2: Pearson's correlation

$\mathrm{NB} ! *$ Correlation is significant at the 0.05 level (2-tailed)

\begin{tabular}{|c|c|c|c|c|c|c|}
\hline & & & & & & $\begin{array}{l}\text { fidence of the } \\
\text { ce }\end{array}$ \\
\hline & $\mathrm{t}$ & df & Sig. (2-tailed) & Difference & Lower & Upper \\
\hline $\mathrm{BO}$ & 24.511 & 199 & .000 & 2.092 & 1.92 & 2.26 \\
\hline WL & 35.959 & 199 & .000 & 3.758 & 3.55 & 3.97 \\
\hline
\end{tabular}

Table 3: Workload (WL) and Nurses Burnout (BO)

Table 3 provides for a calculated $t$ value of 24.511 in respect of the dimension of burnout. Standardized t-distribution value tables in statistical texts provide for a tabled t-value of 1.98 at a significance level of 0.05 and $\mathrm{df}=119$. Since $24.511>1.98$ the null hypothesis is rejected, meaning that high workload at the hospital is likely to lead to high burnout among nursing staff.

\section{Discussions}

We decided to carry out this study amongst nurses because they make up the biggest number of staff members and not because they are the only ones affected by heavy workload. Secondly, nurses form different departments/units of the hospital were included for uniformity purposes since nurses' roles are almost similar across all departments.

A total of 120 nurses and midwives, 82(68\%) of whom were females, participated in the study (Figure 1). Although majority of the respondents, 40(33.3\%), were from maternity ward (Figure 2 ), only $6 \%$ of them were midwives (Figure 3 ). This could probably mean that staff on maternity 


\section{International Journal of Medical Science and Health Research}

Vol. 5, No. 03; 2021

ISSN: $2581-3366$

ward perform duties that they are not trained to do. Could this be a reason for staff burnout? Sometimes employees get stressed because they may not have the appropriate skills to perform certain tusks demanded from them i.e. there is a misfit between skill and demand.

In this article we define burnout as a psychological and emotional syndrome which includes emotional exhaustion (a loss of enthusiasm in one's work), depersonalization (a distorted perception of oneself that leads to lack of empathy and sometimes viewing people as objects) and a low sense of personal accomplishment.

According to Khdour and colleagues, there are many factors that cause burnout, heavy workload and a meaningless job being some of them (Khdour et al., 2015). One of the causes of high workload is staff shortage.

In this study, one hundred and seven (107) (89.2\%) respondents agreed, 90(75\%) of whom strongly agreed, that there is serious shortage of nursing staff in their facility (Figure 4). Shortage of staff means that some staff members are either allocated more duties than they are supposed to perform during a certain work shift, or they chose to work overtime for a pay. The latter is commonly practiced in the two Windhoek state hospitals - Katutura and Windhoek Central Hospitals. This definitely causes staff exhaustion and therefore burnout among the few that are available in the facility. This study has shown that 91(75\%) of the nurses regularly get burnout (Figure 5 \& Table 2).

The Pearson correlation in Table 2 indicates that there is a significant positive relationship between workload and nurse burnout. This accentuates the fact that when workload increases, burnout levels also increase as represented by the co-efficient of 0.258 . On the other hand, there is a significant negative relationship between workload and mental health represented by the coefficient of -0.398. This means that higher workload levels bring about significant negative mental health problems

Table 3 gives for a calculated $t$ value of 24.511 in respect of the dimension of burnout. Standardized $t$-distribution value tables in statistical texts provide for a tabled $t$-value of 1.98 at a significance level of 0.05 and $\mathrm{df}=119$. A $t$ of 24.511 signifies that high workload at the hospital is likely to lead to high burnout among nursing staff.

Symptoms of burnout: In this study, we found that 50(42\%) of the respondents often feel chronically fatigued; 22(18\%) get symptoms of forgetfulness while 15(12.5\%) reported getting insomnia. Other symptoms reported included anxiety (8.3\%) and depression (8.3\%), loss of appetite, mood swings and frequent illness (Figure 6). Definitely it goes without saying that where there is understaffing the available slim staff have to do extra work and, if this becomes a daily routine, has a toll on the staff's private time and physical well-being just as most of them reported that they feel chronically fatigued or emotionally exhausted. Emotional exhaustion eventually leads to loss of enthusiasm of one's work and eventually underperformance. On the other hand, when staffs are faced with multiple tasks at the same time, forgetfulness is unavoidable. This study is supported by the study done by Maslach C, Leiter MP, (2016) who 


\section{International Journal of Medical Science and Health Research}

Vol. 5, No. 03; 2021

ISSN: 2581-3366

found that people who are struggling to cope with work stress may be at high risk of burnout. Burnout can leave people feeling exhausted, empty, and unable to cope with the demands of life. She further stated that burnout may be accompanied by a variety of mental and physical health symptoms as well. If left unaddressed, burnout makes it difficult for an individual to cope with work and other daily activities.

Effects of burn out: The consequences of burnout are not exclusive unto themselves. They often overlap and interrelate with one another. They often present as symptoms and or signs of a mental problem, depression or a major depressive disorder. Major depressive disorder symptoms include the following (American Psychiatric Association):

- Depressed mood

- Diminished ability to think or concentrate

- Diminished interest or loss of pleasure in almost all activities

- Fatigue or loss of energy

- Feeling of worthlessness

- Psychomotor agitation or retardation

- Recurrent thoughts of death, suicidal ideation without a specific plan, or a suicidal attempt or specific plan to commit suicide

- Significant weight loss or disturbance in appetite

- Sleep disturbance which may be either insomnia or hypersomnia

As seen in figure 6, majority (50) (41.7\%) of the respondents indicated that they often feel chronically fatigued; $22(18.3 \%)$ indicated that they get symptoms of forgetfulness; $15(12.5 \%)$ indicated that they get insomnia; $10(8.3 \%)$ indicated they get anxiety; (10) $(8.3 \%)$ indicated that they suffer from depression and (9) (7.5\%) reported loss of appetite. Other symptoms included mood swings and frequent illness. It should be noted that the fatigue identified here does overlap with other co-varying factors.

The effect of chronic fatigue and poor personal health may be late coming to work stations, chronic absenteeism, erratic drug administration and poor relationship with the clients/patients. Khamisa, Peltzer, Ilic \& Oldenburg (2016) stated that burnout among nurses/midwives is associated with absenteeism, lack of job satisfaction, high turnover rates and lack of commitment to the work. All these result in reduced productivity which farther enhances employees' stress.

Poor relationship with clients/patients may be exhibited in form of verbal insults and/or physical abuse of patients like beating. Most of these nursing staff may not have identified that they have a mental/psychiatric problem that requires medical intervention or counselling, but their problems really need to be addressed. In fact, as much as two thirds of people with depression do not realise that they have a treatable illness and therefore do not seek professional help. In their study on Anxiety and depression in the working population using the HAD Scale, Andrea et al. found that the prevalence of anxiety and depression is considerable among employees, and that anxiety may partly be conceptually different from depression. (Andrea et al. 2004) 


\section{International Journal of Medical Science and Health Research}

Vol. 5, No. 03; 2021

ISSN: 2581-3366

Majority 78(65\%) of the respondents in this study indicated that they have no time for social life. Forty-three (43) of the respondents indicated that they have little time for socialization; 31 respondents indicated that burn out leads to poor quality of patient care; 17 respondents indicated that burn out leads to poor family relationships and sometimes breakdown of relationships; 19 respondents indicated that personal health is affected as a result of burnout. Other effects of burnout identified in this study include lack of job satisfaction and poor working relationship with colleagues. As a result of lack of socialization and breakdown in relationship, some staff have thought of leaving the profession. In fact, majority of the respondents (57\%) have at one moment considered leaving the nursing profession.

When a staff leaves the profession or position, s/he leaves increased work stress for the remaining staff. Additionally, as experience comes with time, loss of experienced staff leads to poor quality of patient care. Usually getting another staff with similar experience is not only difficult but also expensive. The cost of training and development for a single new employee is equivalent to that employee's annual income and sometimes more (Campbell 2002).

\section{Conclusion}

The results of this study from Katutura Hospital, Windhoek, Namibia have showed that nursing shortage is a contributing factor to high workload among the nurses in the hospital. The high workload experienced by the nurses has in turn resulted in burnout. This burnout presents itself in form of mental/psychological symptoms which in the long run affects service delivery to clients/patients. There is need for Ministry of Health and Social Services to devise means of reducing the nurses' workload by hiring and retain skilled nurses. It is also be important to motivate the current small number of staff struggling to fulfil the work that would have been by a big team. Mamikhani, et al stated that nursing professionals are the most important human resources that provide care in the Emergency Departments at hospitals; therefore, appropriate compensation for the services they provided should be considered a priority. (Mamikhani, et al (2013).

\section{Acknowledgments}

The researchers would like to thank the Ministry of Health and Social Services in Namibia, to grand her permission to carry out her study in their health facility. Appreciation goes to those avail themselves to participate in this study.

\section{Conflict of interest}

The authors declare that they have no conflict of interest.

\section{References}

American Psychiatric Association. Diagnostic and Statistical Manual of Mental Disorders, Fifth Edition. Washington DC: American Psychiatric Association; 2013

Andrea, H., Bultmann, U., \& Swaen, G. (2004). Anxiety and depression in the working population using the HAD Scale. Social psychiatry and psychiatric epidemiology. 39, 637-646. 


\section{International Journal of Medical Science and Health Research}

Vol. 5, No. 03; 2021

ISSN: $2581-3366$

Arash, N., Ali, M., \& Gholamreza, S. (2012). Causes of job stress in nurses: A cross-sectional study. Iranian Journal of nursing and midwifery research. 17. 301-5.

Campbell, Brenda. 2002. The high cost of turnover. Black Enterprise, December, online at http://www.blackenterprise.com/ArchiveOpen.asp?Source=ArchiveTab/2002/12/120219. htm

Cooper, C. L. (2012). Theories of Organizational stress. Oxford, UK: Oxford University Press.

De Jonge, J., \& Hammers, J.P.H. (2000). Efforts and rewards in work of nurses and carers. 15: 64-73.

Foley, M. (2004). Caring for those who care: A tribute to nurses and their safety. Online Journal of issues in nursing, 9(3).

Kelchtermans, G., Ballet, K., \& Piot, L. (2009). Surviving diversity in times of performativity: Understanding teachers' emotional experience of change. In P. Schutz \& M. Zembylas (Eds.), Advances in teacher emotional research: The impact on teachers' lives (pp. 215232). Dordrecht: Springers.

Khamisa, N., Oldenburg, B., Pelzer, K., \& Ilic, D. (2016). Work related stress, burnout, job satisfaction and general health of nurses. International journal of environmental research and public health, 12(1), 652-666.

Khdour, N., Durrah,O., \& Harris, M. (2015). The effect of job burnout on employee's satisfaction: A comparison study between public universities and private universities in Jordan. Journal of Management Research, 7(4), 54-81.

Mamikhani, J., Tifighi, S., Sadeghifar, J., \& Heidari, M. (2013). Prioritizing the compensation mechanisms for nurses working in emergency department of hospital: a survey from Iran. Global Health Science, 6(2), 86-93.

Maslach C, Leiter M.P. Understanding the burnout experience: recent research and its implications for psychiatry. World Psychiatry. 2016;15(2):103-111. doi:10.1002/wps.20311

Najimi, A., Goudarzi A., \& Sharifirad, G. (2012). Causes of job stress in nurses: Acrosssectional study. Iranian journal of nursing and midwifery research, 17(4), 301.

Rothmann, S. (2009). Occupational stress of nurses in South Africa. SA Journal of Industrial Psychology, 55, 34-41.

Schaufeli, W. B., \& Buunk, B. P. (2003). Burnout: An overview of 25 years or research and

Soegoto, E. S., \& Narimawati, U. (2017). The contribution of stress management and good employee performance towards the success of a company. The Open Psychology Journal, 10(1).

Tummers, G.E.R., Van Merode, G.G. \& Landeweerd, J.A. (2002). The diversity of work differences, similarities, and relationships concerning characteristics of the organization, the work and psychological work reactions in intensive care and non-intensive care nursing. International Journal of Nursing Studies, 39, 841-855. 